\title{
Osteonecrosis in a patient with Crohn's disease unrelated to corticosteroid use
}

\author{
Ali Khan $\mathrm{MD}^{1}$, Gerald Illiffe $\mathrm{MD}^{2}$, Donald S Houston $\mathrm{MD} \mathrm{PhD}^{2}$, Charles N Bernstein $\mathrm{MD}^{2,3}$
}

\begin{abstract}
A Khan, G Illiffe, DS Houston, CN Bernstein. Osteonecrosis in a patient with Crohn's disease unrelated to corticosteroid use. Can J Gastroenterol 2001;15(11):765-768. Osteonecrosis is a feared complication of corticosteroid use. However, a direct association between corticosteroid use and osteonecrosis has never been proven. The present report examines the case of a patient with longstanding Crohn's disease who had never been treated with corticosteroids and who developed osteonecrosis of the talus. The association of systemic inflammatory disorders with osteonecrosis and the possible association with vascular thrombosis are discussed.
\end{abstract}

Key Words: Corticosteroids; Crohn's disease; Osteonecrosis

\section{Ostéonécrose chez un patient souffrant de la maladie de Crohn, non liée aux corticostéroïdes}

RÉSUMÉ : L'ostéonécrose est une complication redoutée des corticostéroïdes. Toutefois, le lien direct entre les deux n'a jamais été établi. Voici le cas d'un patient souffrant depuis longtemps de la maladie de Crohn, qui n'a jamais été traité aux corticostéroïdes et chez qui est apparue une ostéonécrose de l'astragale. Il sera donc question, dans le présent article, du lien entre les troubles inflammatoires généraux et l'ostéonécrose et du lien possible avec la thrombose vasculaire.
$\mathrm{O}$ steonecrosis is a disorder characterized by death of the cellular elements of the bone. It has been associated with many disorders, but knowledge of its pathophysiology remains incomplete. One association is with the use of corticosteroids, including their use in patients with inflammatory bowel disease (IBD). The mechanism of steroidinduced osteonecrosis remains obscure. Some people have questioned whether osteonecrosis that occurs in patients given corticosteroids for chronic inflammatory diseases is actually due to the underlying systemic disease rather than the corticosteroids, although corticosteroids may play a permissive role (1). Systemic lupus erythematosis (SLE) is one chronic inflammatory disease in which the association with osteonecrosis has been widely described. Two cases of osteonecrosis have been reported in patients with Crohn's disease before they began taking corticosteroids (2). Relatively few patients with IBD who take corticosteroids suffer from osteonecrosis. Whether or not corticosteroids contribute to the risk of osteonecrosis, there may be other described factors that predispose some patients with IBD to this bone complication.

Osteonecrosis in patients with IBD may cause significant symptoms and have a considerable impact on quality of life. For physicians, there may be medicolegal implications (3). Despite that it has been shown that corticosteroids do not cause osteonecrosis in normal animal models $(1,4,5)$ and that there is some suggestion that the underlying systemic disease is important to the osteonecrosis process, physicians have been found liable in cases brought forth by patients who required and used corticosteroids for appropriate indications

Departments of ${ }^{1}$ Surgery and ${ }^{2}$ Internal Medicine, and ${ }^{3}$ University of Manitoba Inflammatory Bowel Disease Clinical and Research Centre, University of Manitoba, Winnipeg, Manitoba 

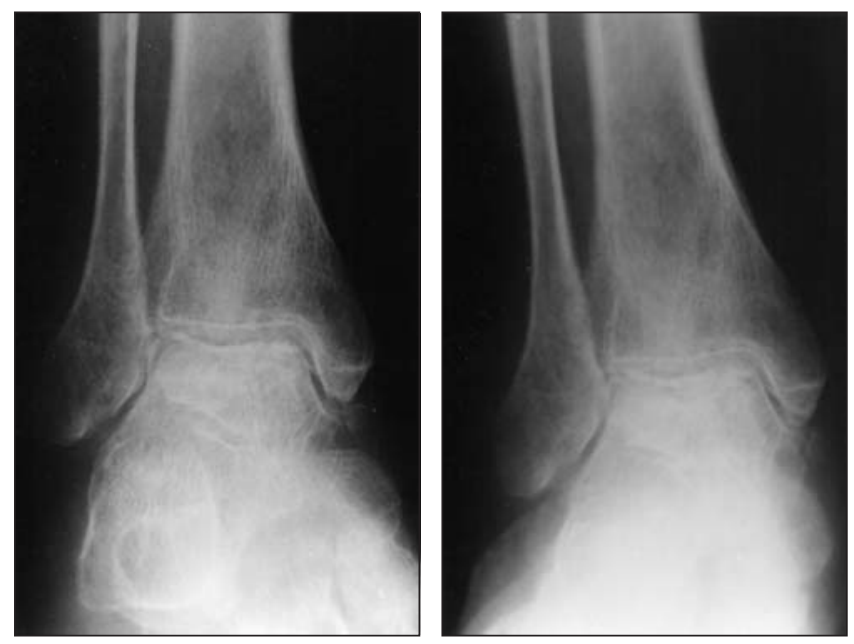

Figure 1) Plain films of ankles. The bones are generally undermineralized. There is extensive soft tissue swelling around the ankle. The findings are indicative of advanced avascular necrosis of the talar domes. Left Fracture is evident at the tip of the medial malleolus; there is fissuring, sclerosis and irregularity at the dome of the talus. Right There is evident flattening or collapse of the talar dome

but who suffered from osteonecrosis (3). We report a patient with Crohn's disease of 30 years' duration who had never been treated with corticosteroids and who presented with osteonecrosis of the talus. This case provides further evidence that osteonecrosis in a patient with Crohn's disease may be more likely to be disease-related than corticosteroid-related.

\section{CASE PRESENTATION}

In 1966, a 14-year-old female patient presented with abdominal pain, diarrhea, weight loss and anorexia, and a perianal fistula. Sigmoidoscopy revealed distal colorectal inflammation. She was treated with antibiotics. Nine months later, she underwent a laparotomy, which revealed a thickened, indurated and adherent terminal ileum, ascending colon and proximal one-third of the transverse colon. An ileal resection plus right hemicolectomy with end-to-end ileocolonic anastamosis was performed. The pathology was consistent with Crohn's disease. In 1968, the patient underwent a second laparotomy for recurrent obstructive symptoms. At surgery, the patient was found to have a thickened and edematous colon with a normal small bowel. The ileocolonic anastamosis was resected, and a permanent ileostomy was created.

Over the next nine years, the patient was hospitalized five times per year, on average, for intermittent bowel obstructions. She was treated medically with sulfasalazine $1.5 \mathrm{~g} / \mathrm{day}$, and at no time did she receive corticosteroids. In 1977, she underwent a third laparotomy, which revealed a thickened mesentery, and a stenotic and thickened distal ileum. Twelve centimetres of neoterminal ileum was resected, and the end ileostomy was recreated.

Over the ensuing 19 years, she had multiple hospitalizations for recurrent small bowel obstructions. Her medical management as an inpatient never included corticosteroids, and as an outpatient, she was maintained on 5-aminosali- cylic acid (Asacol, Procter \& Gamble Pharmaceuticals, Canada) and cod liver oil for the latter 15 years. During disease exacerbations, she frequently complained of diffuse arthralgias, but she never suffered from frank arthritis.

In 1996, she was admitted with an incomplete small bowel obstruction. At that time, she complained of increased arthralgias at her ankles, hips, hands and left knee. She had sustained no trauma to any of her joints. She gave no history of alcohol ingestion and had never been treated with total parenteral nutrition (TPN). On physical examination, she had abdominal findings consistent with a small bowel obstruction and bilateral ankle swelling. Her ankle $\mathrm{x}$-rays revealed collapse, with subchondral sclerosis of the talar dome consistent with osteonecrosis, and there also were secondary osteoarthritic degenerative changes (Figure 1). There was osteopenia at her left hip and knee, and her wrists and sacroiliac joint $\mathrm{x}$-rays were normal. At this time, her hemoglobin level was $136 \mathrm{~g} / \mathrm{L}$; her platelet count initially was 580,000 and rose as high as 762,000 . Her erythrocyte sedimentation rate was $83 \mathrm{~mm} / \mathrm{h}$. Tests for anti-DNA and anticardiolipin antibodies, rheumatoid factor, C3 and C4, and serum cryoglobulins were negative. She was weakly positive for antinuclear antibodies, which had a homogenous speckled pattern. A Venereal Disease Research Laboratory test was nonreactive. The partial thromboplastin time was $32 \mathrm{~s}$, and the international normalized ratio was 1.20 . Left ankle aspirate revealed no crystals and a negative culture. The patient's Crohn's disease continued to be managed conservatively without corticosteroids or surgery. Her ankle osteonecrosis was managed with patellar tendon-bearing splints.

In October 1998, the patient was admitted for active Crohn's disease and was found to have an intra-abdominal abscess requiring laparotomy with debridement, further ileal resection, abdominal fascial closure requiring Marlex mesh (CR Bard, USA) and resiting of her end ileostomy. During this admission, the patient complained of ongoing arthralgias, and limited range of hip and ankle movement. $\mathrm{X}$-rays revealed a normal lumbosacral spine and hips, and bilateral talus deformities with sclerosis and lucencies consistent with osteonecrosis. A bone scan revealed increased uptake at both ankle joints.

She was readmitted in April 1999 for high output enterocutaneous fistula via the Marlex mesh. Initial management was gut rest, and, for the first time in the patient's medical history, TPN was initiated. In August 1999, the patient underwent resection of small bowel and the fistula tract, along with abdominal wall reconstruction. She was treated only with Asacol. The osteonecrosis of her ankles remained a formidable issue in terms of symptoms and ambulation. No new changes were noted radiographically. Ultimately, mobilization has improved with the assistance of her ankle prostheses. At no time has she ever been treated with corticosteroids.

A coagulation profile was undertaken because of the possibility that hypercoagulability may be an important etiological factor in osteonecrosis. Blood was analyzed during a 
time of disease quiescence for a variety of coagulation parameters. Protein $\mathrm{C}$, protein $\mathrm{S}$ and antithrombin III levels were within normal limits. The factor $\mathrm{V}$ Leiden or prothrombin mutations were not present. The serum homocysteine level was elevated at $16.7 \mu \mathrm{mol} / \mathrm{L}$ (normal less than $13 \mu \mathrm{mol} / \mathrm{L}$ ), and the factor VIII level was markedly elevated at $538 \%$. Her tissue plasminogen activator antigen level was elevated at $12.1 \mathrm{ng} / \mathrm{mL}$ (normal 1.4 to $8.4 \mathrm{ng} / \mathrm{mL}$ ), and the plasminogen activator inhibitor (PAI) activity was at the upper end of normal at $10.6 \mathrm{U} / \mathrm{mL}$ (normal less than 0.1 to $11.0 \mathrm{U} / \mathrm{mL}$ ). Her lipoprotein (a) level was $449 \mathrm{U} / \mathrm{L}$ (normal 0 to $300 \mathrm{U} / \mathrm{L}$ ). At the time that these levels were measured, the C-reactive protein level was less than $4 \mathrm{mg} / \mathrm{L}$.

\section{DISCUSSION}

Our patient developed osteonecrosis after nearly 30 years of recurrently active Crohn's disease without ever being treated with corticosteroids. Osteonecrosis was reported in the early part of the 20th century, long before corticosteroids were introduced therapeutically (6). There has been a paucity of reports of osteonecrosis in IBD. It was first reported in a patient with Crohn's disease taking corticosteroids and was then reported in three teenagers who were receiving corticosteroids plus TPN for active Crohn's disease $(7,8)$. Because the authors of the pediatric series had not seen osteonecrosis previously among their patients with Crohn's disease treated with corticosteroids or among their TPN-treated patients, they postulated that the mechanism was based on the combination of corticosteroid use and TPN (perhaps through elevated lipid profiles systemically and locally within bones) (8). Later, seven patients (4.3\%) in a series of 161 corticosteroid-treated Crohn's disease patients were reported to have osteonecrosis (9). The authors concluded that corticosteroids were to blame for the osteonecrosis in their IBD patients. However, there was no control group of IBD patients who had not received corticosteroids. In this study, the mean cumulative dose of prednisone was only $7 \mathrm{~g}$, whereas in two other series of patients with organ transplants or SLE who developed osteonecrosis, the mean cumulative prednisone doses were 42 and $45 \mathrm{~g}$, respectively $(10,11)$. This may further support the hypothesis that IBD itself poses a risk for the development of osteonecrosis. In a number of reports of patients with SLE, no relationship was evident between corticosteroid dose, duration of use or cumulative dose and development of osteonecrosis (11-14).

Kenzora and Glimcher (1) suggested that corticosteroids alone likely do not cause osteonecrosis. Administration of corticosteroids to healthy laboratory animals has failed to induce osteonecrosis $(1,4,5)$. In humans, there have been few reported cases of osteonecrosis developing in patients receiving corticosteroids for nonsystemic medical problems. None of 6000 head trauma patients treated with high dose corticosteroids over a 10 -year period at the University of Maryland (College Park, USA) developed osteonecrosis (1).
A hypothesis that has been put forward regarding the pathogenesis of osteonecrosis is impaired vascular flow to bone, with subsequent cell death. One mechanism postulated for the impaired flow is vascular thrombosis; patients with IBD have increased rates of venous thromboembolism (15), and some investigators have postulated a vasculitis theory of Crohn's disease pathogenesis (16). In one series of patients with idiopathic osteonecrosis (not associated with any underlying inflammatory condition or use of corticosteroids), 15 of 18 patients had a definable disorder predisposing them to thrombosis (17). In this report, there were three subjects with osteonecrosis who had no underlying associated risk factor of any type, including systemic disease, corticosteroid use, or a definable thrombophilic or hypofibrinolytic disorder. There is one case report in the literature of a child with severe protein $\mathrm{C}$ deficiency who presented with hip osteonecrosis at a time when therapeutic coumadin administration led to a suboptimal international normalized ratio (18). The formation of small fibrin thrombi in the circulation of patients with Crohn's disease may lead to osteonecrosis by progressively occluding epiphyseal capillaries (19). Perhaps the strongest evidence for a correlation between hypercoagulability and osteonecrosis is a study that reported 59 patients with hip osteonecrosis, of whom $41 \%$ were homozygous for the $4 \mathrm{G} / 4 \mathrm{G}$ polymorphism of the PAI- 1 gene compared with $20 \%$ of a control group $(\mathrm{P}=0.001)(20)$. The gene product of the $4 \mathrm{G}$ polymorphism, hypofibrinolytic PAI activity, was higher in osteonecrosis patients than in controls (median $19.2 \mathrm{U} / \mathrm{mL}$ versus $6.3 \mathrm{U} / \mathrm{mL}, \mathrm{P}=0.0001$ ).

Our patient had a very elevated level of circulating factor VIII, a mildly elevated level of homocysteine and a high lipoprotein (a) level. These were measured during a period of inactive inflammatory disease (corroborated by the level of C-reactive protein) and thus are likely constitutional. Both elevated factor VIII and elevated homocysteine levels can predispose a person to vascular thrombosis (21-24), although neither has been associated with osteonecrosis thus far. Disturbances of fibrinolysis, particularly, elevation of lipoprotein (a), have been the most common abnormalities identified in osteonecrosis (17). Impaired fibrinolysis has also been reported to be a feature of Crohn's disease (18). Another hypothesized mechanism for osteonecrosis that arises in patients with multisystem diseases is the impairment of osteoblast function by circulating cytokines (25). The lack of osteoblasts to repair small microfractures may increase the susceptibility of a person to osteonecrosis by another factor such as corticosteroids. However, we propose that the predisposition to thrombosis may be an important factor associated with osteonecrosis, particularly during periods of increased disease activity.

\section{CONCLUSIONS}

We report the case of a patient with longstanding Crohn's disease who never used corticosteroids and who presented with osteonecrosis of the talus. This patient had some abnormalities in coagulation parameters. We contend that 
hypercoagulability may be related to osteonecrosis. Therefore, consideration should be given to checking the coagulation profiles of patients with unexplained osteonecrosis. Osteonecrosis in Crohn's disease remains sufficiently uncommon; it is thus premature to consider screening all patients with Crohn's disease for coagulation parameters. Corticosteroids may contribute to the risk profile of osteonecrosis, but this remains only conjecture. As our case proves, osteonecrosis can occur in patients with Crohn's disease who do not use corticosteroids.

ACKNOWLEDGEMENTS: Charles $\mathrm{N}$ Bernstein $\mathrm{MD}$ is supported by a Manitoba Medical Services Foundation Clinical Research Professorship. Donald S Houston MD PhD is supported by the Heart and Stroke Foundation of Canada.

\section{REFERENCES}

1. Kenzora JE, Glimcher MJ. Accumulative cell stress: the multifactorial etiology of idiopathic osteonecrosis. Orthop Clin North Am 1985;16:669-79.

2. Freeman HJ, Kwan WCP. Non-corticosteroid-associated osteonecrosis of the femoral heads in two patients with inflammatory bowel disease. N Engl J Med 1993;329:1314-6.

3. Carter RM. Malpractice and avascular necrosis. Legal outcomes. Can J Gastroenterol 1999;13:79-84.

4. Fisher DE, Bickel WH, Holley KE, Ellefson RD. Corticosteroidinduced aseptic necrosis. Part II: Experimental study. Clin Orthop 1972;84:200-6.

5. Jaffe WL, Epstein M, Heyman N, Mankin HJ. The effect of cortisone on femoral and humeral heads in rabbits: An experimental study. Clin Orthop 1972;82:221-8.

6. Kahlstrom SC, Burton CC, Phemister DB. Aseptic necrosis of bone. I. Infarction of bones in Caisson disease resulting in encapsulated and calcified areas in diaphyses and in arthritis deformans. Surg Gynecol Obstet 1939;68:129-46.

7. Brom B, Bank S, Marks IN, Cobb JJ. Periostitis, aseptic necrosis and arthritis occurring in a patient with Crohn's disease. Gastroenterology 1971;60:1106-9.

8. Shapiro SC, Rothstein FC, Newman AJ, Flether B, Halpin TC Jr. Multifocal osteonecrosis in adolescents with Crohn's disease: a complication of therapy? J Pediatr Gastroenterol Nutr 1985;4:502-6.
9. Vakil N, Sparberg M. Steroid-related osteonecrosis in inflammatory bowel disease. Gastroenterology 1989;96:62-7.

10. Creuss R. Cortisone-induced avascular necrosis of the femoral head. J Bone Joint Surg Br 1977;59:308-17.

11. Zizic TM, Marcoux C, Hungerford DS, Dansereau JV, Stevens MB. Corticosteroid therapy associated with ischemic necrosis of bone in systemic lupus erythematosis. Am J Med 1985;79:596-602.

12. Dimant J, Gingler EM, Diamond HS, et al. Computer analysis of factors influencing the appearance of aseptic necrosis in patients with SLE. J Rheumatol 1978;5:136-41.

13. Dubois EL. Lupus Erythematosis, 2nd edn. Los Angeles: University of Southern California Press, 1974:332-42,424-6.

14. Abeles M, Urman JD, Rothfield N. Aseptic necrosis of bone in systemic lupus erythematosis: relationship to corticosteroid therapy. Arch Intern Med 1978;138:750-4.

15. Bernstein CN, Hopper Y, Blanchard JF. The incidence of deep venous thrombosis and pulmonary emboli among patients with IBD: A population-based cohort study. Gastroenterology 1999;116:A668. (Abst)

16. Wakefield AJ, Sankey EA, Dhillon AP, et al. A granulomatous vasculitis in Crohn's disease. Gastroenterology 1990;100:1279-87.

17. Glueck CJ, Freiburg R, Tracy T, Stroop D, Wang P. Thrombophilia and hypofibrinolysis. Pathophysiologies of osteonecrosis. Clin Orthop 1997;334:43-56.

18. Wermes C, Bergmann F, Reller B, Sykora KW. Severe protein C deficiency and aseptic osteonecrosis of the hip joint: a case report. Eur J Pediatr 1999;158(Suppl 3):S159-61.

19. De Jong E, Porte RJ, Knot EAR, Verheijen JH, Dees J. Disturbed fibrinolysis in patients with inflammatory bowel disease. A study in blood plasma, colon mucosa, and faeces. Gut 1989;30:188-94.

20. Glueck CJ, Fontaine RN, Gruppo R, et al. The plasminogen activator inhibitor-1 gene, hypofibrinolysis, and osteonecrosis. Clin Orthop 1999;366:133-46.

21. Koster T, Blann AD, Briet E, Vandenbroucke JP, Rosendaal FR. Role of clotting factor VIII in effect of von Willebrand factor on occurrence of deep-vein thrombosis. Lancet 1995;345:152-5.

22. O'Donnell J, Tuddenham EG, Manning R, Kemball-Cook G, Johnson D, Laffan M. High prevalence of elevated factor VIII levels in patients referred for thrombophilia screening: role of increased synthesis and relationship to the acute phase response. Thromb Haemost 1997;77:825-8.

23. Kamphuisen PW, Eikenboom JCJ, Vos HL, et al. Increased levels of Factor VIII and fibrinogen in patients with venous thrombosis are not caused by acute phase reactions. Thromb Haemost 1999;81:680-3.

24. den Heijer M, Rosendaal FR, Blom HJ, Bos GM.

Hyperhomocysteinemia and venous thrombosis: a meta-analysis. Thromb Haemost 1998;80;874-7.

25. Manolagas SC, Jilka RL. Bone marrow, cytokines and bone remodeling. Emerging insights into the pathophysiology of osteonecrosis. N Engl J Med 1995;332:305-11. 


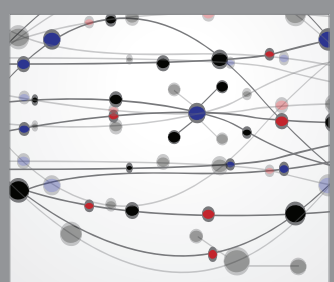

The Scientific World Journal
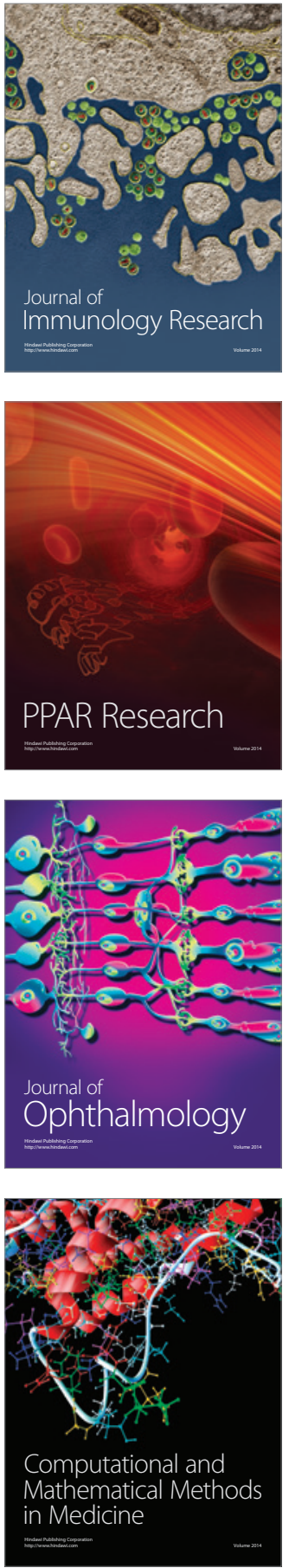

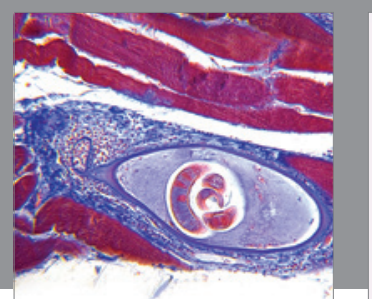

Gastroenterology Research and Practice

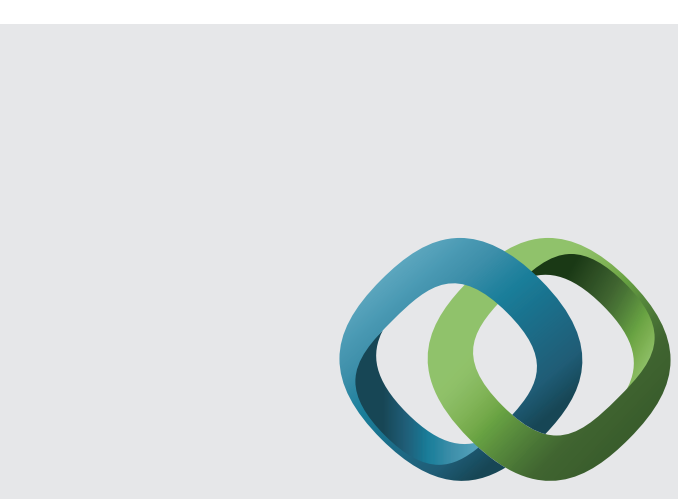

\section{Hindawi}

Submit your manuscripts at

http://www.hindawi.com

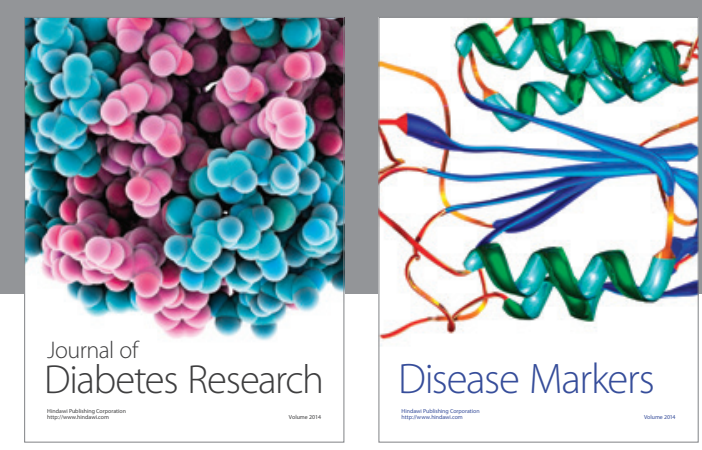

Disease Markers
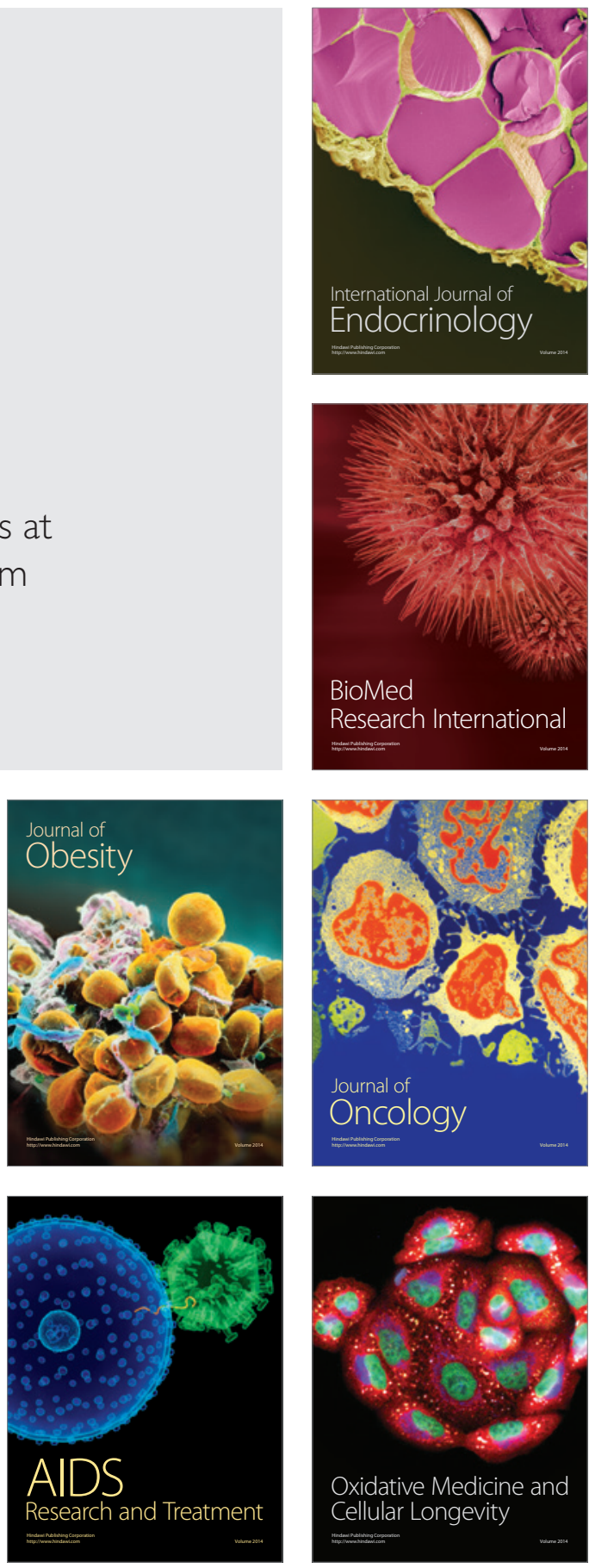